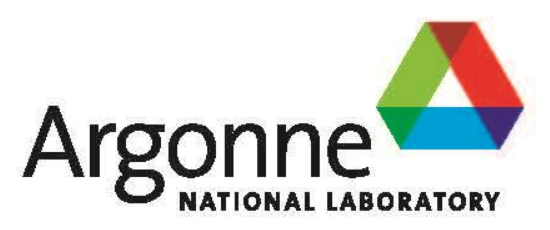

ANL/NE-15/2

\title{
Micro-Bubble Experiments at the Van de Graaff Accelerator
}

Nuclear Engineering Division 


\begin{abstract}
About Argonne National Laboratory
Argonne is a U.S. Department of Energy laboratory managed by UChicago Argonne, LLC under contract DE-AC02-06CH11357. The Laboratory's main facility is outside Chicago, at 9700 South Cass Avenue, Argonne, Illinois 60439. For information about Argonne and its pioneering science and technology programs, see www.anl.gov.
\end{abstract}

\title{
DOCUMENT AVAILABILITY
}

Online Access: U.S. Department of Energy (DOE) reports produced after 1991 and a growing number of pre-1991 documents are available free via DOE's SciTech Connect (http://www.osti.gov/scitech/).

Reports not in digital format may be purchased by the public from the National Technical Information Service (NTIS):

U.S. Department of Commerce

National Technical Information Service

5301 Shawnee Rd

Alexandria, VA 22312

unw.ntis.gov

Phone: (800) 553-NTIS (6847) or (703) 605-6000

Fax: (703) 605-6900

Email: orders@ntis.gov

Reports not in digital format are available to DOE and DOE contractors from the Office of Scientific and Technical Information (OST):

U.S. Department of Energy

Office of Scientific and Technical Information

P.O. Box 62

Oak Ridge, TN 37831-0062

unw.osti.gov

Phone: (865) 576-8401

Fax: (865) 576-5728

Email: reports@osti.gov

\section{Disclaimer}

This report was prepared as an account of work sponsored by an agency of the United States Government. Neither the United States Government nor any agency thereof, nor UChicago Argonne, LLC, nor any of their employees or officers, makes any warranty, express or implied, or assumes any legal liability or responsibility for the accuracy, completeness, or usefulness of any information, apparatus, product, or process disclosed, or represents that its use would not infringe privately owned rights. Reference herein to any specific commercial product, process, or service by trade name, trademark, manufacturer, or otherwise, does not necessarily constitute or imply its endorsement, recommendation, or favoring by the United States Government or any agency thereof. The views and opinions of document authors expressed herein do not necessarily state or reflect those of the United States Government or any agency thereof, Argonne National Laboratory, or UChicago Argonne, LLC. 


\section{Micro-Bubble Experiments at the Van de Graaff Accelerator}

by

Z.J. Sun, K. Wardle, K. Quigley, R. Gromov, A.J. Youker,

V. Makarashvili, J. Bailey, D. Stepinski, S. Chemerisov, and G.F. Vandegrift

Nuclear Engineering Division, Argonne National Laboratory

prepared for

U.S. Department of Energy, National Nuclear Security Administration,

Office of Defense Nuclear Nonproliferation

February 2015 



\section{CONTENTS}

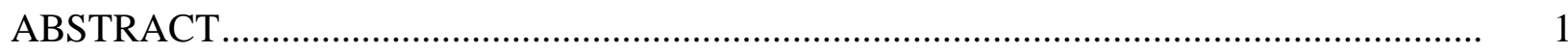

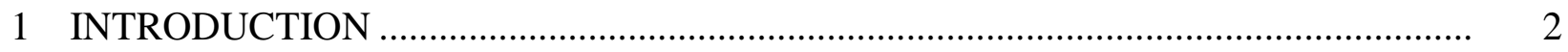

2 EXPERIMENTAL SETUPS AND PROCEDURES .......................................................... 3

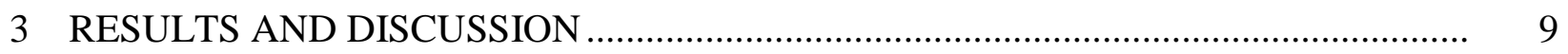

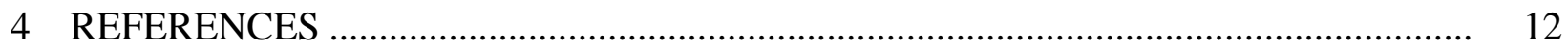

\section{FIGURES}

1 Beam Manipulation in the Micro-Bubble Experiments: Trapezoidal Beam Pipe at the End of Beam Line; Beam Profiles Shown by Radiation-Damaged Pyrex Cover Slides; and Power Supplies and Pulse Generator to Control the Current in the Raster Magnets

2 Irradiation-Target and $\mathrm{NaHSO}_{4}$ Solution Preparation: Dimensions of the Square Quartz Tube; Glass Beads Placed in the Quartz Tube to Raise the Level of Solution; Top of the Quartz Tube in the Experiments; and Degasser for Preparing the Target Solution

3 Cameras and Camera-Controlling System: Color Camera, which is Manipulated by the Hand Shank in the Control Room; LabVIEW Program for Controlling the Monochromatic Camera; and MayTec Rack and Rails for the Monochromatic Camera

4 Gas Analysis System and Fluctuation in Gas Generation: Flowchart of the Gas Analysis System; Valves and Flow Controls in Actual Experimental Setup; Peaksimple Analysis Software, Version 3.85; and Fluctuation of Hydrogen Generation in One of the Irradiations.

5 MCNPX Simulation Results for Micro-Bubble Experiments--Power Deposition in the Water

6 Bubble Generation in the VDG Experiments: Bubble Formation and Cherenkov Radiation in Irradiation; Bubble "Storm" when the Beam Current Increased; and Big Bubble Bursting into a Group of Tiny Bubbles 


\section{TABLE}

$1 \quad$ Model and Frame Rate for USB 3.0 Cameras ................................................... 6 


\begin{abstract}
In order to test and verify the experimental designs at the linear accelerator (LINAC), several micro-scale bubble ("micro-bubble") experiments were conducted with the 3-MeV Van de Graaff (VDG) electron accelerator. The experimental setups included a square quartz tube, sodium bisulfate solution with different concentrations, cooling coils, gas chromatography (GC) system, raster magnets, and two high-resolution cameras that were controlled by a LabVIEW program. Different beam currents were applied in the VDG irradiation. Bubble generation (radiolysis), thermal expansion, thermal convection, and radiation damage were observed in the experiments. Photographs, videos, and gas formation $\left(\mathrm{O}_{2}+\mathrm{H}_{2}\right)$ data were collected. The micro-bubble experiments at VDG indicate that the design of the full-scale bubble experiments at the LINAC is reasonable.
\end{abstract}




\section{INTRODUCTION}

The purpose of the bubble experiments is to study the thermal hydraulics of the solution volume (a sector of SHINE solution vessel) under a high irradiation field of the electron beam generated by the LINAC accelerator. The focus of the research is the radiolysis in the solution (especially on bubble formation), bubble behavior, and thermal dynamics of the solution. Data collected from these experiments will serve as a means to validate computer models, which include the thermal hydraulics model created by ANSYS and the nuclear radiation model generated by MCNPX.

Before conducting the full-scale bubble experiments at the LINAC, we performed several micro-bubble experiments at the 3-MeV Van de Graaff (VDG) accelerator in order to test the experimental designs and validate the feasibility of bubble experiments at the LINAC. The goals for the micro-bubble experiments were to test:

- Beam Manipulation: Raster magnets, power supplies, and pulse generators were tested for defocusing/spreading the electron beam into the whole beam window to irradiate the target solution evenly.

- Radiation Stability: All the experimental setups (the quartz tube, thermal couples, high resolution cameras, USB cables, etc.) needed to fulfill mechanical and radiation-stability requirements. If they failed at the VDG, there would be no chance for them to survive the harsh radiation environment in the LINAC vault.

- Data-Acquisition System: The data-acquisition equipment gathers and stores information from the cameras, thermocouples, and gas-analysis system (gas chromatography). The hardware and software of those measurement devices must function well and work as expected.

In addition, bubble generation and thermal hydraulics of the solution were expected to be seen in the micro-bubble experiments. It would be encouraging to find that the phenomena we observed are consistent with the results of computer simulations. 


\section{EXPERIMENTAL SETUPS AND PROCEDURES}

The experimental setup of the micro-bubble experiment was composed of several independently working systems: -magnet and electronics for beam manipulation (Figure 1), target (Figure 2), lights and cameras (Figure 3), and gas analyzer (Figure 4). Each system is described below.

\section{Beam Manipulator}

The experiments were performed on the zero-degree port of the VDG. A trapezoidal beam pipe (Figure 1 (a)) was installed at the end of the beam. Two raster magnets, which are responsible for the vertical and horizontal deflection of the beam, were installed on the straight pipe right before the trapezoidal end to defocus and/or spread the beam. Two bipolar operation power suppliers (KEPCO BOP 50-8M) with one pulse generator (TEKTRONIX J310400) were used to introduce currents into the raster magnets to elongate the initial circular-shaped electron beam. Electronic pulses with different shapes (e.g., triangle, rectangular, cosine, Gaussian, etc.) and frequency were overlaid on the currents in the power suppliers. The aim of the beam manipulation was to fill the beam within the whole window and distribute incoming electrons evenly on the incident surface of the target solution.

Before we started the target solution irradiation, several clear plastic sheets (1/4-in. thick) were exposed at the end of the beam line for short (5-sec) irradiations. These irradiationdamaged plastic sheets were scanned, and each of them generated a unique beam profile for the corresponding beam and raster magnets parameters.

\section{Target}

The target solution system consisted of a square quartz tube, two NPT fitting ends, sodium-bisulfate solution, cooling coils, and three thermocouples. The dimensions of the square quartz tubes are shown in Figure 2(a).

The wall facing the cameras is a 3-mm-thick optical-grade quartz plate. The other three walls are 1.2-mm thick. At the ends of the tube, Ultra-Torr to NPT adapters with NPT end cups were installed. For the bottom NPT fitting, a tiny hole (1/64-in. diameter) was drilled, and an OMEGA TMQSS-O20V-12 T type thermocouple was inserted. For the top adapter, two 1/64-in. holes were drilled for thermocouples, and four 1/8-in. holes for the cooling coils (1/8-in. SS304 tubing). In addition, gas tubes were linked to the headspace of the solution. After insertion of the thermocouples and tubes, all the holes were completely sealed with epoxy glue.

The target solution was $\mathrm{NaHSO}_{4}$. Previous irradiations at the VDG indicated that bubble formation of high concentration $\mathrm{NaHSO}_{4}$ was significant $[1,2]$. The concentration and $\mathrm{pH}$ of the target solutions used in the micro-bubble experiments are as follows: (1) $1.3 \mathrm{M}$ and $\mathrm{pH}=1.28$; (2) $1.26 \mathrm{M}$ and $\mathrm{pH}=1.03$. Before the electron irradiation, the target solution was sparged with 2 psi helium gas for half an hour. The sparging device is shown in Figure 2(d). To raise the 


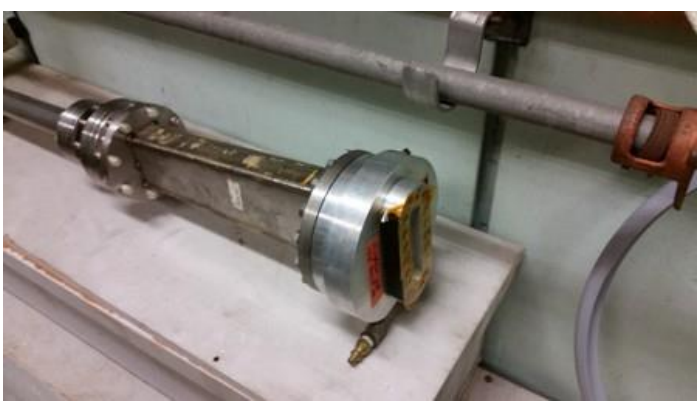

(a)

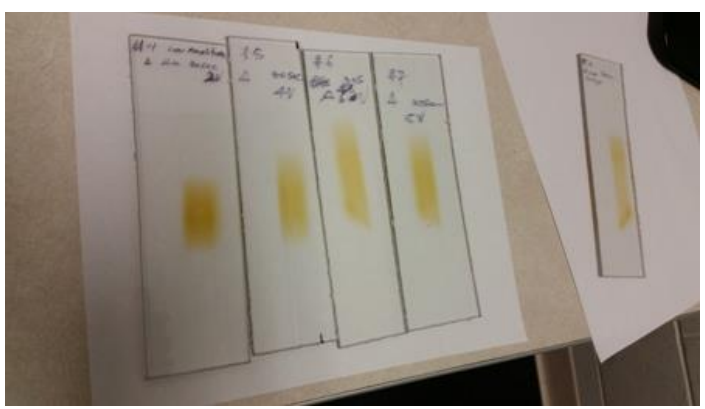

(b)

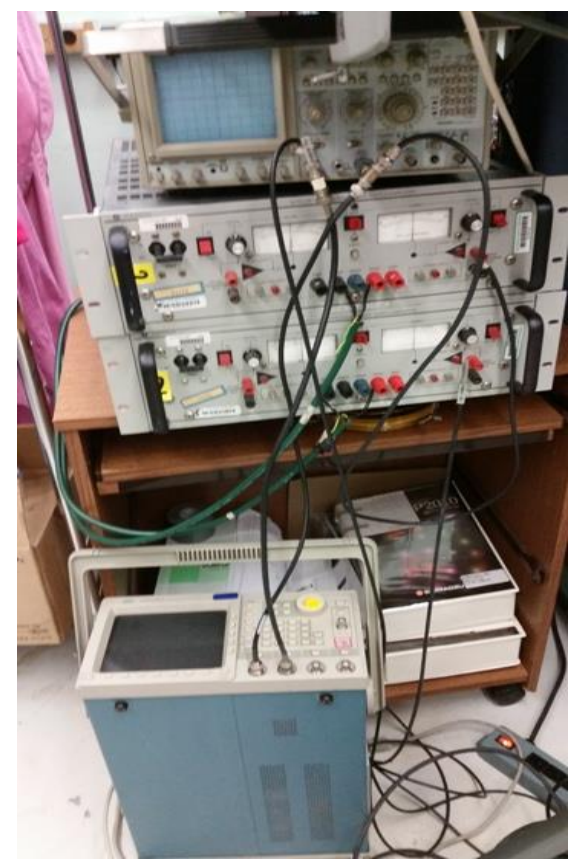

(c)

FIGURE 1 Beam Manipulation in the Micro-Bubble Experiments: (a) Trapezoidal Beam Pipe at the End of Beam Line; (b) Beam Profiles Shown by RadiationDamaged Pyrex Cover Slides; and (c) Power Supplies and Pulse Generator to Control the Current in the Raster Magnets

solution level so that the cooling coil is immersed in the top section of the solution, we placed glass beads (1/8-in. diameter) into the quartz tube in some later micro-bubble experiments.

\section{Lights and Cameras}

Two cameras were used for the VDG experiments (Table 1). Initially, IP color cameras were used to obtain an overview of the experimental setup. However, because the Ethernet cable of the IP cameras cannot function well in a high radiation field at the VDG, the IP cameras were replaced by two PointGrey USB 3.0 cameras: a monochromatic camera (Grasshopper3 GS3-U323S6M-C) for details and a color one (Flea3 FL3-U3-88S2C-C) for overview (Figure 3). The color camera was positioned in an adjustable stand that was remotely controlled by a hand shank in the control room. The high-resolution monochromatic camera was installed on a MayTec rack. The rack has both vertical and horizontal rails, and the camera can move slowly $(1 \mathrm{~mm} / \mathrm{sec})$ along the rails powered by an electronic motor. The motor was controlled by a computer outside the irradiation room through a USB 3.0 cable. A LabVIEW program was designed to control the position of the camera. Rulers and deep-wedge meters were placed at the end of the beam line for focusing the cameras.

The lights in the radiation room were bright enough for use of the color camera. However, the high-definition monochromatic camera needs a stronger backlight since it only 


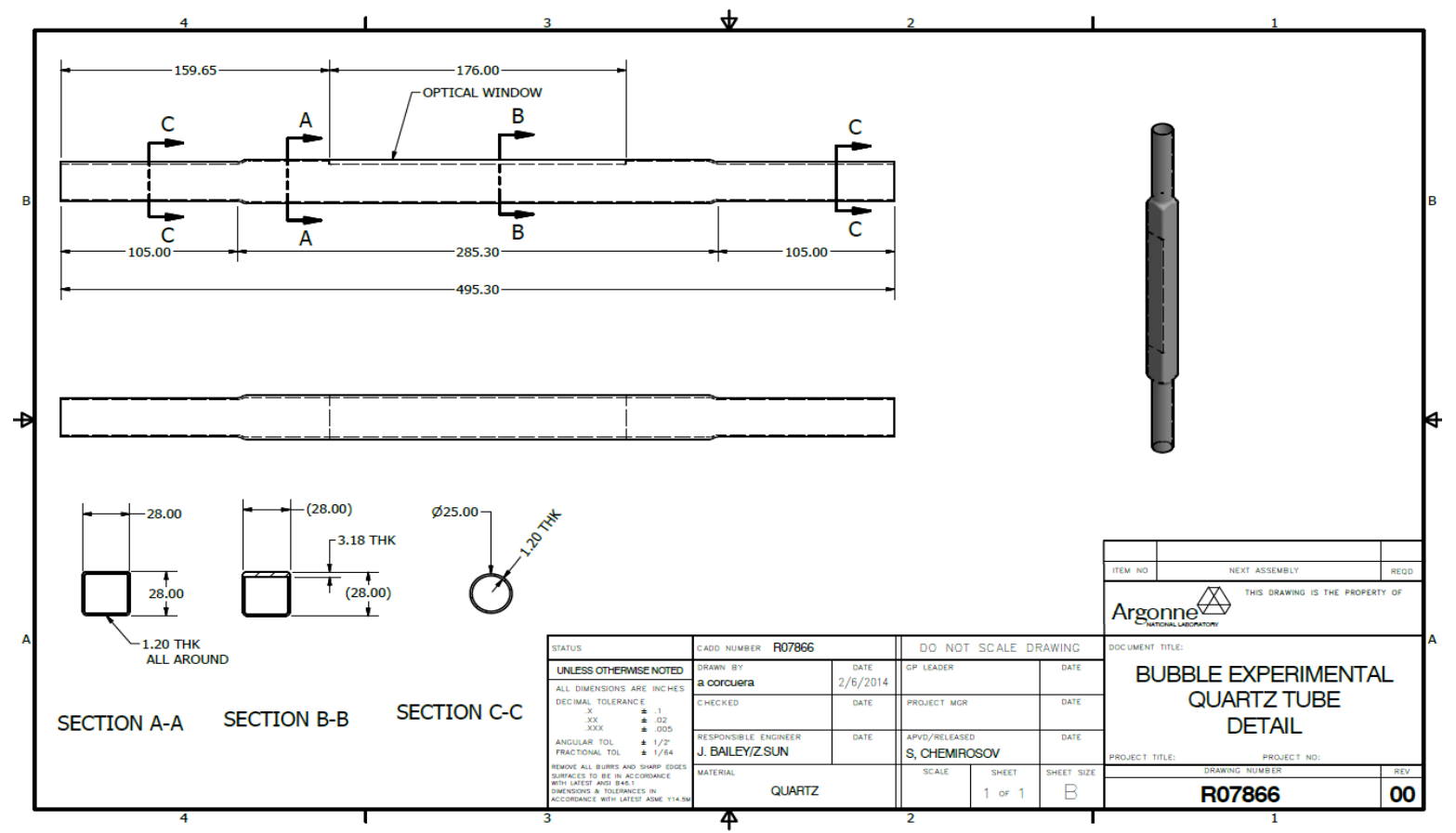

(a)

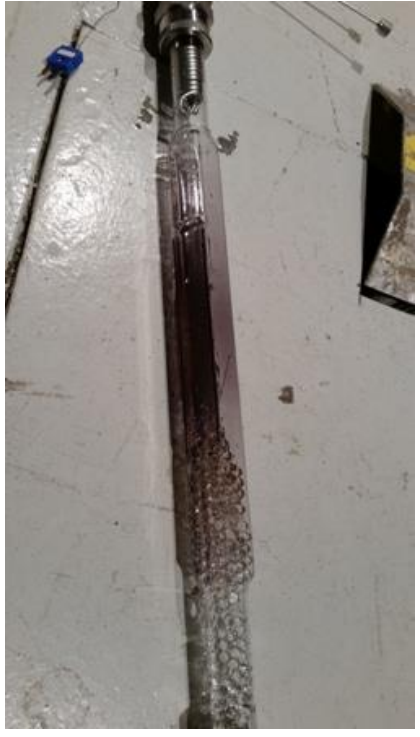

(b)

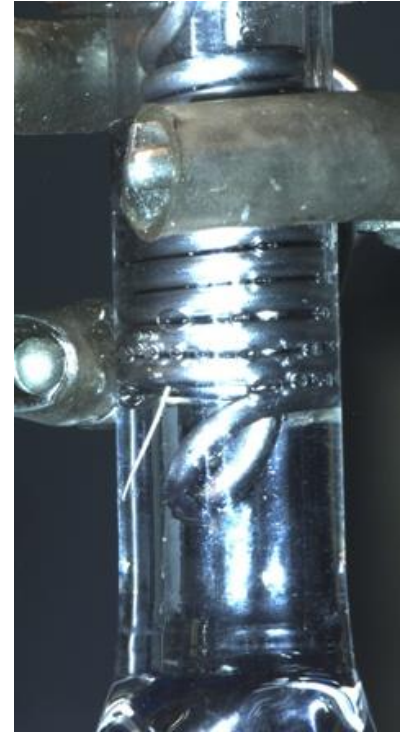

(c)

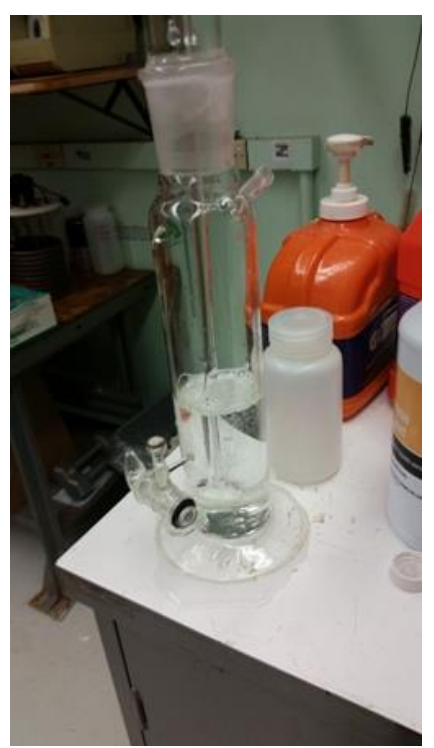

(d)

FIGURE 2 Irradiation-Target and $\mathrm{NaHSO}_{4}$ Solution Preparation: (a) Dimensions of the Square Quartz Tube; (b) Glass Beads Placed in the Quartz Tube to Raise the Level of Solution; (c) Top of the Quartz Tube in the Experiments (thermocouple, cooling coils, and generated bubbles); and (d) Degasser for Preparing the Target Solution 
TABLE 1 Model and Frame Rate for USB 3.0 Cameras

\begin{tabular}{|c|c|c|}
\hline Camera & Model & $\begin{array}{l}\text { Frame Rate } \\
\text { @ Resolution }\end{array}$ \\
\hline CAM1 & $\begin{array}{l}\text { PointGrey Grasshopper3, } \\
\text { Model GS3-U3-23S6M-C }\end{array}$ & $\begin{array}{l}160 \text { frames/second } \\
\text { @ } 2.3 \mathrm{MP} \text { (monochrome) }\end{array}$ \\
\hline CAM2 & $\begin{array}{l}\text { PointGrey Flea3, } \\
\text { Model FL3-U3-88S2C-C }\end{array}$ & $\begin{array}{l}21 \text { frames/second } \\
\text { @ } 8.8 \mathrm{MP} \text { (color) }\end{array}$ \\
\hline
\end{tabular}

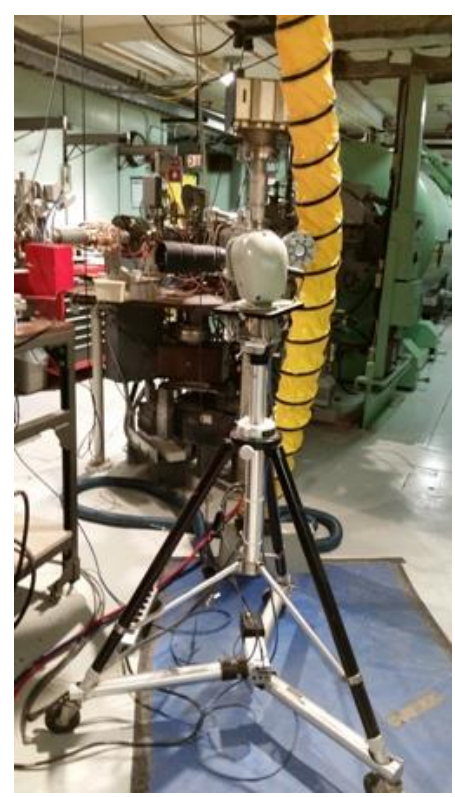

(a)

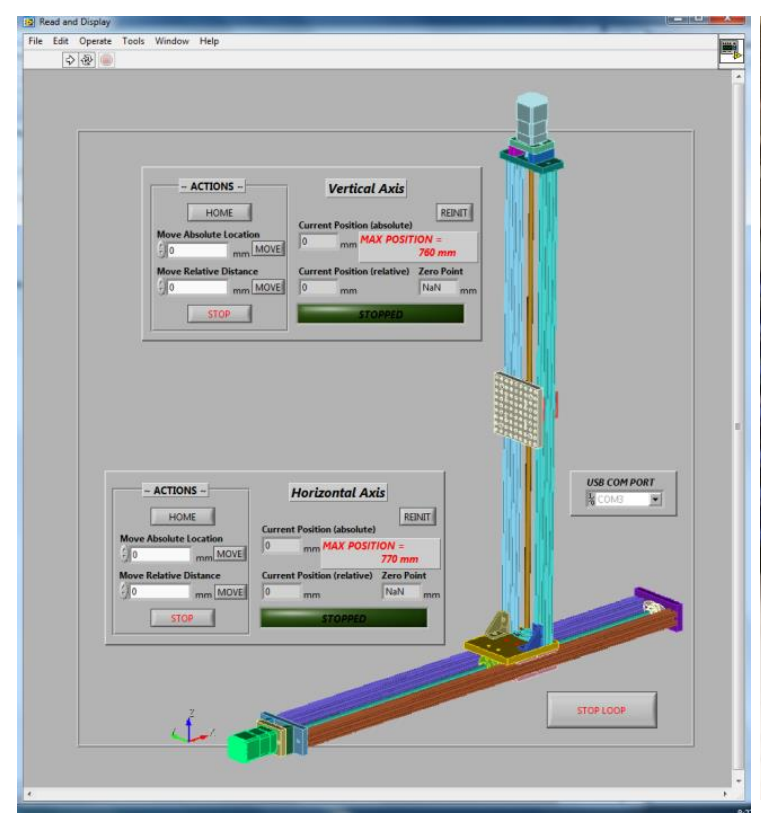

(b)

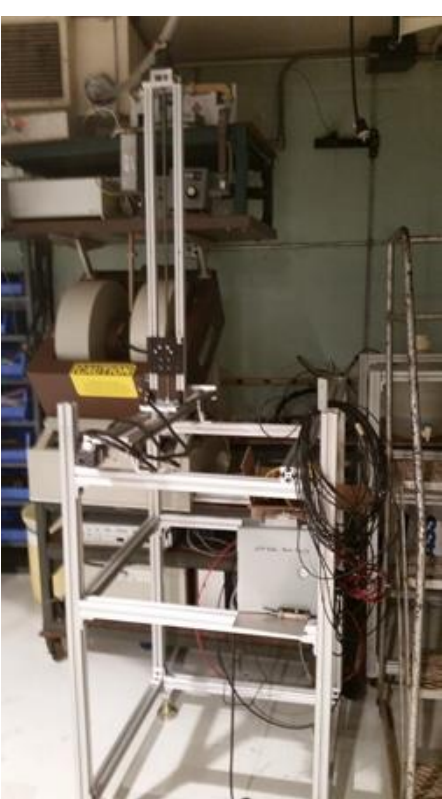

(c)

FIGURE 3 Cameras and Camera-Controlling System: (a) Color Camera (Flea3 FL3-U3-88S2C-C), which is Manipulated by the Hand Shank in the Control Room; (b) LabVIEW Program for Controlling the Monochromatic Camera; and (c) MayTec Rack and Rails for the Monochromatic Camera

looks at a very small area. An LED light $(100 \mathrm{~W})$ with cooling fins was placed at the back side of the quartz tube to illuminate the view captured by the monochromatic camera.

\section{Gas Analysis}

Figure 4(a) shows the experimental arrangement of the gas analysis system. Figure 4(b) is a picture of the valves, flow controllers, pressure meters, and stainless-steel tubing of the gas analysis system. The gas composition is measured by a gas chromatograph (GC) equipped with helium ionization and thermal conductivity detectors. Data were recorded and analyzed by the Peaksimple (version 3.85) software (Figure 4(c)). The measurements for each data point took 


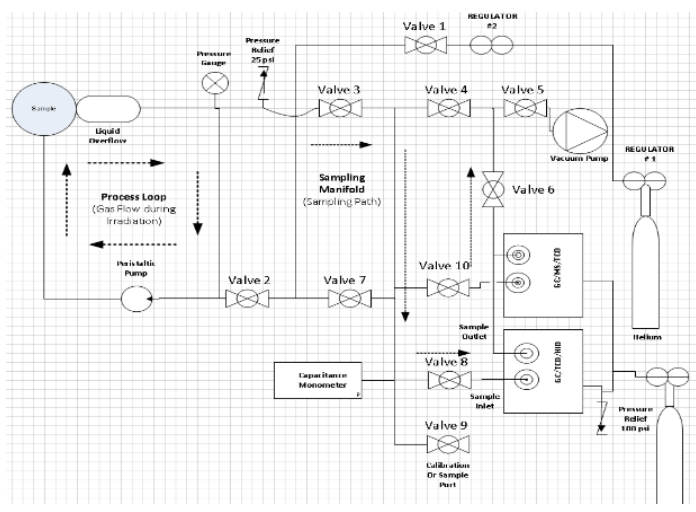

(a)

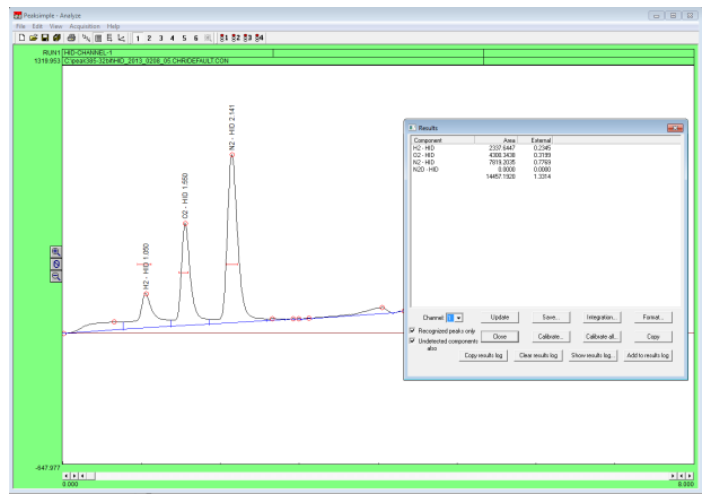

(c)

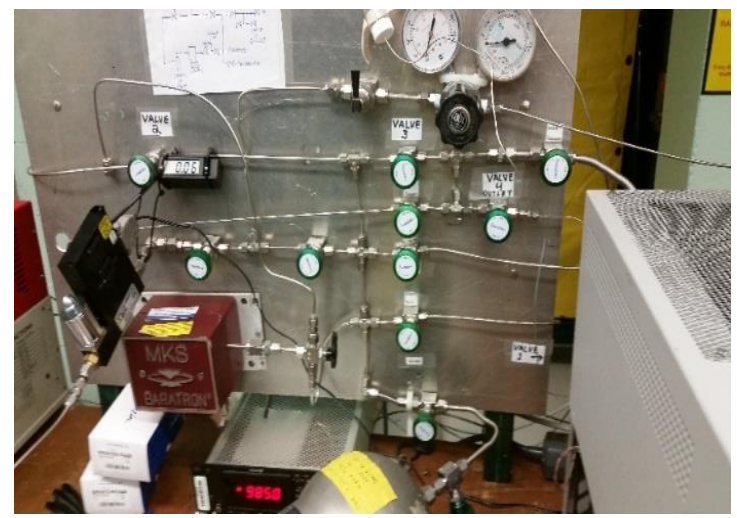

(b)

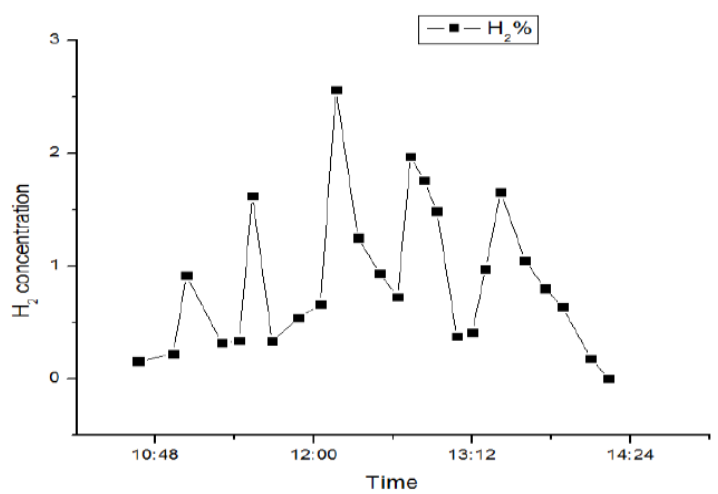

(d)

FIGURE 4 Gas Analysis System and Fluctuation in Gas Generation: (a) Flowchart of the Gas Analysis System; (b) Valves and Flow Controls in Actual Experimental Setup; (c) Peaksimple Analysis Software, Version 3.85 (the three peaks correspond to $\mathrm{H}_{2}, \mathrm{O}_{2}$, and $\mathrm{N}_{2}$ ); and (d) Fluctuation of Hydrogen Generation in One of the Irradiations

about 5 min. The $\mathrm{GC}$ was calibrated with $\mathrm{H}_{2}$ and $\mathrm{O}_{2}$ gas standards. The details of the gas analysis system are described in Ref. 1.

\section{Computer Simulations}

MCNPX was used as the primary code to simulate the energy deposition processes during the irradiation. The results are shown in Figure 5. The plot shows the power deposition of electrons in the water solution. 


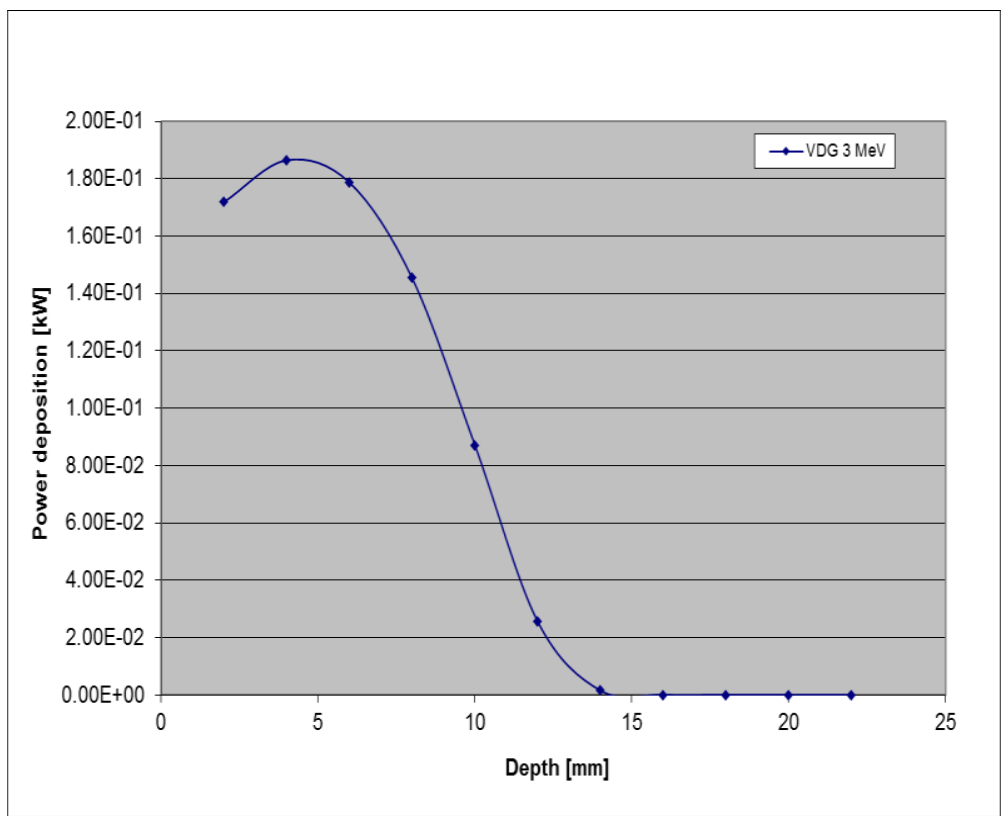

FIGURE 5 MCNPX Simulation Results for Micro-Bubble Experiments--Power Deposition in the Water 


\section{RESULTS AND DISCUSSION}

The primary conclusion of these experiments is that the concepts developed for the LINAC bubble experiment are well founded, and several improvements for the experiment have been derived directly from the VDG testing.

\section{Test of Beam Manipulation}

Experiments have shown that using a raster magnet to control the electron beam is feasible. We successfully changed the beam shape via the raster magnets with different shape and frequency of pulses controlling the power supplies (vertical and horizontal). The beamprofile study indicated that a triangle-shaped pulse was the best option to create an evenly distributed beam. However, in the beam-manipulation process, a potential risk is that the beam could deviate so much as to heat the gaskets of the beam pipes and thereby cause a vacuum loss to the whole beam line. Therefore, a beam-monitoring device is necessary for the bubble experiment at the LINAC.

\section{Radiation Stability}

Most of the experimental setup (thermocouples, high resolution cameras, USB 3.0 cables, etc.) passed the mechanical and radiological test at the VDG. However, passing the test at the VDG does not mean those devices can survive the harsh radiation field in the LINAC vault. For the bubble experiments at the LINAC, more shielding is necessary to protect the cameras and the USB 3.0 controller (e.g., the camera should be positioned behind a lead wall to avoid direct shining of X-rays created along the LINAC beam line). In the micro-bubble experiments, the quartz tube changed color to purple after being irradiated by electrons for a fairly long period (Figure 2(b)). However, this radiation damage was reversible: the quartz tube returned to clear transparency after being reheated at the glass shop overnight (13 hours). We expect that similar behavior will be observed on the quartz glass window in the LINAC irradiation.

\section{Data Acquisition System}

The data acquisition system worked well in the micro-bubble experiments. However, some computer programs need further improvement. For instance, a temperature measurement was carried out by the Honeywell Eztrend XQe device, which we found was difficult for manipulating the logging of temperatures. Also, the LabVIEW program for moving the monochromatic camera along the rails lacks a calibration function and cannot indicate the exact coordinates of the position.

\section{Bubble Formation, Cherenkov Radiation, and Thermal Phenomena}

Bubbles, both large and small, were observed simultaneously in the micro-bubble experiments (Figure 6). A blue glow from Cherenkov radiation of electrons was observed as well. However, the glow was not bright enough to eliminate the requirement for external lighting. High-lumen LED lights are needed to illuminate the sample for the black-and-white 


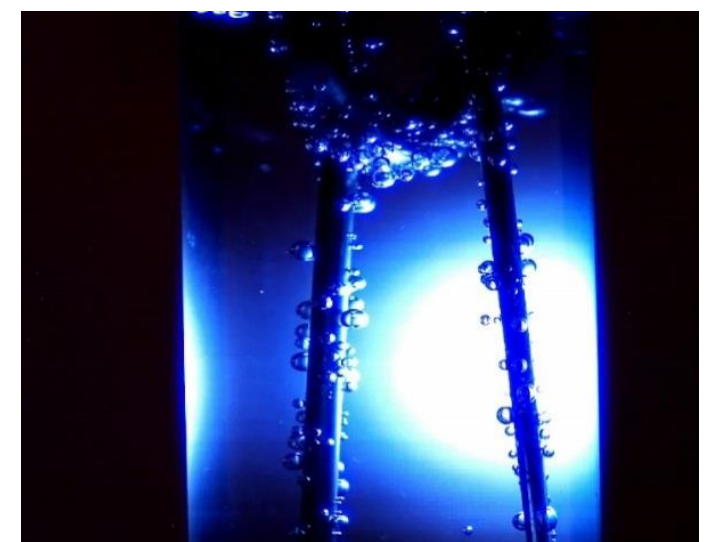

(a)

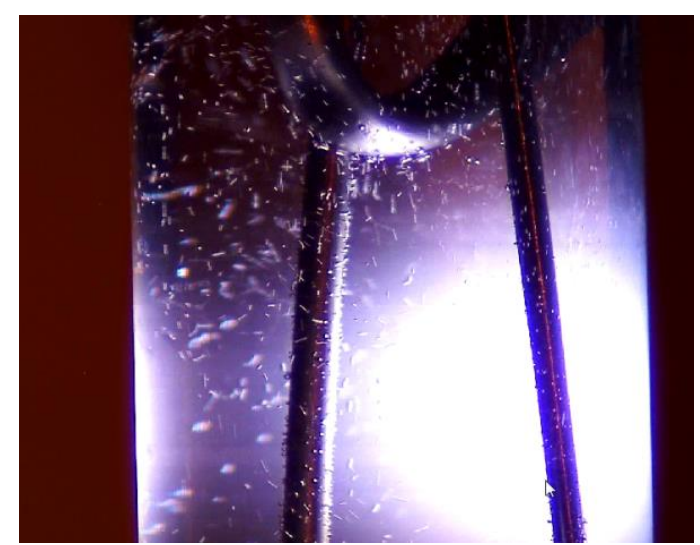

(b)

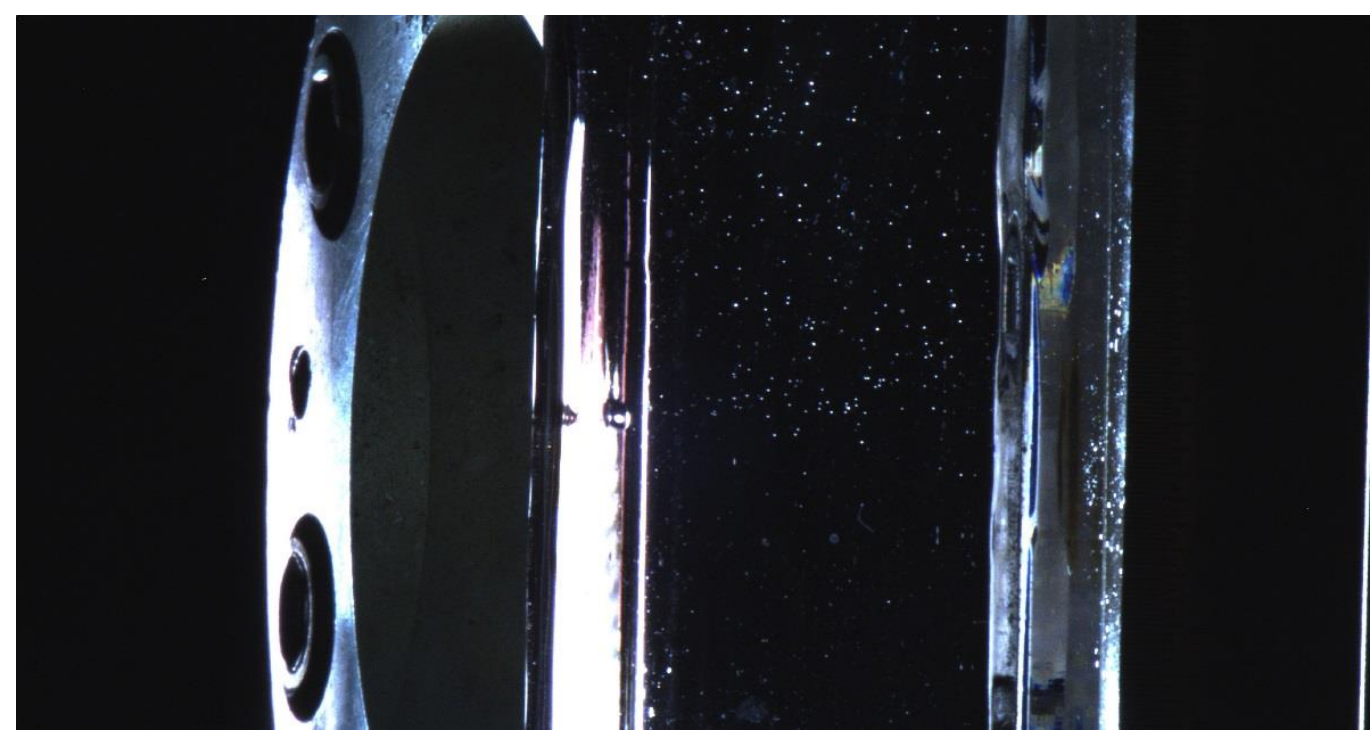

(c)

FIGURE 6 Bubble Generation in the VDG Experiments': (a) Bubble Formation and Cherenkov Radiation in Irradiation; (b) Bubble "Storm" when the Beam Current Increased; and (c) Big Bubble Bursting into a Group of Tiny Bubbles

camera. The high resolution monochromatic camera can track some small bubbles (up to $10 \mu \mathrm{m}$ range) and estimate their sizes and velocities based on the reference rulers and resolution configurations of the camera. The visual area of the monochromatic camera is relatively small, which creates difficulties in tracking bubble movements. Also, significant thermal expansion of the solution, approximately $5 \mathrm{~mL}$ volume, was observed when the solution temperature was increased by $20^{\circ} \mathrm{C}$. This finding is consistent with our calculation based on the thermal expansion coefficient of $\mathrm{NaHSO}_{4}$ solution. Thermal convection was also observed, and the bubbles generated during irradiation followed convection currents.

1 Pictures (a) and (b) were taken with a cylinder glass tube before the fabrication of the square quartz tube. 
For long-duration irradiations, large bubbles were observed at the spot where the electron beam entered the target solution (Figure 6(c)). The initial big bubble grew dramatically and burst into small bubbles. ${ }^{2}$ The thermocouple near the big bubble recorded a temperature around $98^{\circ} \mathrm{C}$. Conceivably, this big bubble originated from the boiling of the target solution. When we controlled the power and kept the solution temperature below $70^{\circ} \mathrm{C}$, only very tiny bubbles (around $50 \mu \mathrm{m}$ ) were created.

\section{Unsteady Gas Generation}

We were expecting the gas generation of the target solution to reach a steady state; however, during the experiments, the hydrogen production varied dramatically and never reached a stable condition (Figure 4(d)). This effect might be due to the unstable inlet helium flow and/or the drifting of the beam current during irradiations.

2 See video at https://www.youtube.com/watch?v=kNiuIdIhBUk. 


\section{REFERENCES}

[1] Michael Kalensky, Sergey Chemerisov, Amanda Youker, Andrew Hebden, Peter Tkac, Vakhtang Makarashvili, Elizabeth Krahn, John Krebs, Kevin Quigley, Robert Lowe, Delbert Bowers, Seema Niak, Don Graczyk, Vivian Sullivan, Allen Bakel, and

George F. Vandegrift, "Radiolysis of Nitrate and Sulfate Solutions," ANL/CSE-13/23, Argonne National Laboratory, November 20, 2012, http://www.ipd.anl.gov/anlpubs/2013/10/76911.pdf.

[2] Michael Kalensky, T. A. Heltemes, J. F. Schneider, D. L. Bowers, S. D. Chemerisov, A. J. Youker, P. Tkac, K. J. Quigley, J. F. Krebs, D. Rotsch, and G. F. Vandegrift, "Measuring Radiolytic- and Fission-Gas Generation in an Aqueous Uranium-Sulfate Target Solution in Accelerator-Based Mo-99 Production”, Mo-99 2014 Topical Meeting, Washington D.C., June 24-27, 2014, http://mo99.ne.anl.gov/2014/pdfs/. 



\section{Argonne}

Nuclear Engineering Division

Argonne National Laboratory

9700 South Cass Avenue, Bldg. 205

Argonne, IL 60439-4837

www.anl.gov

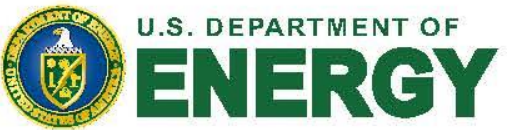

Argonne National Laboratory is a U.S. Department of Energy

laboratory managed by UChicago Argonne, LLC 